\title{
Innervated and vascularized radial thenar flap free grafting for partial penile reconstruction after traumatic penile amputation: a case report and surgical techniques
}

\author{
Hongen Lei ${ }^{1}$ Hu Han ${ }^{1}$, Tiepeng $\mathrm{Ma}^{2}$, Long $\operatorname{Tian}^{1}$ \\ ${ }^{1}$ Department of Urology, Beijing Chao-Yang Hospital, Capital Medical University, Institute of Urology, Capital Medical University, Beijing 100020, \\ China; ${ }^{2}$ Department of Hand Surgery, the Second Hospital of Tangshan, Tangshan 063000, China \\ Correspondence to: Long Tian. Department of Urology, Beijing Chao-Yang Hospital, Capital Medical University, Institute of Urology, Capital Medical \\ University, No. 8 Gongren Tiyuchang Nanlu, Chaoyang District, Beijing 100020, China. Email: longtian@ccmu.edu.cn.
}

\begin{abstract}
Penile amputation is a rare deformity mostly resulting from self-mutilation, felonious assault, or accidental trauma, and penile reconstruction or phalloplasty is necessary when microreplantation cannot be performed. Here we report a rare case of a 42-year-old man with traumatic penile amputation and describe surgical techniques for partial penile reconstruction by using a novel innervated and vascularized radial thenar flap free grafting method. Excellent cosmetic and functional results were reported with no severe complications of dysuria, urethral stricture, and urinary fistula were observed during the 23 months of postoperative follow-up time. It is believed that innervated and vascularized radial thenar flap free grafting is an acceptable treatment option for patients with traumatic penile amputation.
\end{abstract}

Keywords: Radial thenar flap; penile reconstruction; penile amputation; phalloplasty; case report

Submitted Nov 27, 2019. Accepted for publication Dec 10, 2019.

doi: $10.21037 /$ tau.2019.12.12

View this article at: http://dx.doi.org/10.21037/tau.2019.12.12

\section{Introduction}

Penile amputation is an rare deformity mostly resulting from self-mutilation, felonious assault, or accidental trauma (1). Microsurgical penile replantation has good results for this uncommon but challenging disease with a minimum number of post-operative complications, however penile reconstruction or phalloplasty is necessary when microreplantation cannot be performed due to various factors such as the amputated segment is lost (2). Initially, conservative treatments such as division of the suspensory ligament or excision of the suprapubic fat pad can be helpful for those patients who still have an adequate penile length after penile amputation. In the genetic male, surgical indications for penile reconstruction are traumatic amputation, micropenis, aphallia, bladder exstrophy, penectomy for carcinoma, severe penile infection and female-to-male transsexuals (3).

Currently, the radial artery based free flap phalloplasty is the mainstay of phallic replacement procedure for total penile reconstruction both in men and in female-to-male transsexuals (4). Literarily, the microsurgical radial forearm free flap phalloplasty may be the first choice to restore the patient with an acceptable cosmetic and functional phallus, although problematic complications including flap failure, urethral fistula, urethral stricture and stiffener related problems frequently occurred (5). Here we report a rare case and describe surgical techniques for partial penile reconstruction in a man with traumatic penile amputation by using a novel innervated and vascularized radial thenar flap free grafting method, with no severe complications were encountered during the postoperative follow-up period time. We present the following case in accordance with the CARE Guideline.

\section{Case presentation}

A 42-year-old man was initially transferred by ambulance to the emergency department seeking treatment for traumatic 
penile amputation and acute urinary retention caused by pain. The external free portion of the nonerect penis was cut off with a scissor by his mentally ill wife about 8 hours before coming to the hospital, the scrotum and bilateral testicles were intact, and the excised part of the penis was discarded by his wife and was nowhere to be found unfortunately. At the request of the emergency physician, tube cystostomy was performed first of all for acute urinary retention by the urologist. Then, following the emergency debridement in the operation room, the ends of both corpora of the remaining penile stump were closed transversely and urethral meatoplasty was done, a $16-\mathrm{Fr}$ Foley catheter was inserted into the urinary bladder and the cystostomy tube was removed at the same time. A month later, the urethral catheter was removed and the man had adopted a squatting posture during micturition in contrast to a standing posture which he preferred before.

One year later, this man visited the doctor again with the chief complaint of unsatisfactory penile appearance and inability to urinate standing up, eagerly seeking for further phalloplasty and urethoplasty for him. The patient had no dysuria, and no normal sexual intercourse can be fulfilled though he still had erection by the residual penile stump. Physical examination showed that in the flaccid state the residual penile stump was about $2 \mathrm{~cm}$ long and urethral meatus was on the ventral surface of it with no obvious stenosis. After careful evaluation and literature review, as well as obtaining informed consent from the patient, we developed the cosmetic procedure to have the residual penile reconstructed for improving appearance and function by using a radial thenar flap free grafting method.

\section{Surgical techniques}

The surgical procedure was as follows: (I) penile lengthening: the superficial suspensory ligament of the penis was cut out and about $2 \mathrm{~cm}$ long penis was freed from its pubic bone attachments, the stump of the suspensory ligament of the penis was sutured and fixed with the deep fascia of the skin under the pubic mound to prevent the penis from retraction; (II) preparation in recipient area: a segment of the inferior epigastric artery about $12 \mathrm{~cm}$ long, which goes from the point below the inguinal inner circle to the point where the inferior epigastric artery entered the rectus abdominis, was found behind the rectus abdominis and fully dissociated through an incision at the outer edge of the right lower rectus abdominis, the proximal end was cut off and the inferior epigastric artery segment was transferred along the inguinal canal to the root of the penis for artery anastomosis, and the penile deep dorsal vein and the penile dorsal nerve in the residual penile stump were separated for anastomosis as well; (III) radial thenar flap obtaining: a radial thenar flap, which was pedicled with the superficial palmar branch of the radial artery, the superficial branch of the radial nerve, and the cephalic vein, was identified and carefully cut off from the left hand, the size of the flap was about $3.5 \mathrm{~cm} \times 10.5 \mathrm{~cm}$, the skin incision on the radial side of the left hand was sutured with reduced tension; (IV) radial thenar flap free grafting: the free pedicle flap was transplanted to the penile recipient site, the inferior epigastric artery was anastomosed with the superficial palmar branch of the radial artery, the penile deep dorsal vein and the penile dorsal nerve were anastomosed with the cephalic vein and the superficial branch of the radial nerve, respectively (Table 1); (V) phalloplasty and urethoplasty: a 16-Fr Foley catheter was inserted into the urinary bladder, the skin around the residual urethral meatus was turned inwards to form the urethra, and the radial thenar flap was curled toward the middle to form the glans.

\section{Follow-up}

One month after the radial thenar flap free grafting, the urinary catheter was removed and the wounds healed well both on the penis and left upper limb, the patient was very satisfied with the cosmetic effects and he was able to urinate standing up with satisfactory urinary flow. The cosmetic results of the radial thenar flap free grafting are shown in Figure 1. After 23 months of postsurgical followup, no dysuria, no urethral stricture, or urinary fistula was observed, besides, the patient had morning erections and good sensation of the flap-based phallus, though he had not attempted to have sexual intercourse yet.

\section{Discussion}

External genital abnormalities can cause severe physical changes and psychological distress in men, with major clinical manifestations including penile cosmetic changes, inability to micturate in the standing position, and inability to have an erection and penetrative intercourse. Penile reconstruction is badly required in patients with excision of the genitalia due to benign and malignant conditions, traumatic amputation, micropenis and aphallia, and in female-to-male transsexuals (4). Ideally, penile reconstruction should be completed in a single procedure, 
Table 1 Vascular and nerve anastomosis of the thenar flap free grafting

\begin{tabular}{llll}
\hline Flap grafting & Arteries & Veins & Nerves \\
\hline Residual penis (recipient site) & Inferior epigastric artery & Penile deep dorsal vein & Penile dorsal nerve \\
Thenar flap (donor site) & $\begin{array}{l}\text { Superficial palmar branch of the } \\
\text { radial artery }\end{array}$ & Cephalic vein & Superficial branch of radial nerve \\
Suture size & $11-0$ & $9-0$ & $11-0$ \\
Suture number & 8 sutures & 8 sutures & 3 sutures \\
\hline
\end{tabular}
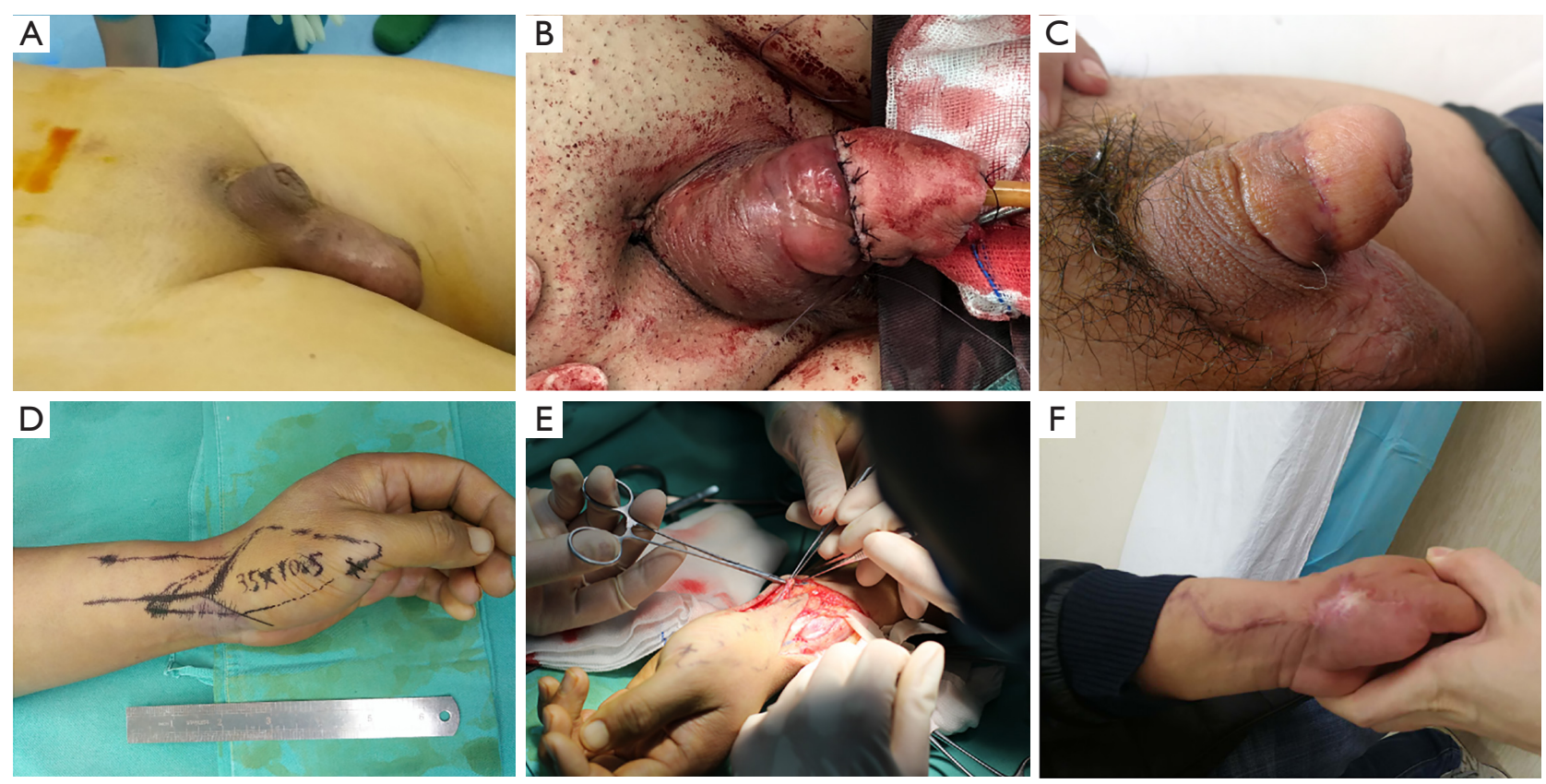

Figure 1 The cosmetic results of the radial thenar flap free grafting for partial penile reconstruction. (A,B,C) Penile appearance at the time points of before surgery, during surgery, and 3rd month after surgery, respectively; (D,E,F) forearm appearance at the time points of before surgery, during surgery, and 3rd month after surgery, respectively.

be aesthetically acceptable, retain tactile and erogenous sensation, enable micturition while standing, and allow for penetrative sexual intercourse (6). To date, given the complexity of the anatomy and physiology of the penis and the fact that there is no good substitute for the erectile tissue of the corpora, there is still no ideal gold standard operation or no consensus among surgeons regarding the most optimum method to have phalloplasty.

Numerous techniques ranging from local pedicled and distant free flaps for phalloplasty to penile transplants have been attempted to reconstruct the penis, but none fulfils all the criteria and is universally accepted as an ideal method. Literarily, the radial forearm free flap is the most preferred technique for total penile reconstruction, and other techniques including the fibular osteocutaneous flap, anterolateral thigh flap, latissimus dorsi flap, scapular free flap, and abdominal flap are described (7). Currently, surgeons are rather required to mix and match a couple of surgical techniques in order to have an ideal aesthetic and functional outcome (8). The vascularized radial artery free flap (RAFF) phalloplasty may be the first choice for surgeons because of its reliable and excellent cosmetic and functional results, although no controlled prospective randomized studies are available to confirm that. The patients with the radial forearm phalloplasty are always able to void standing and in most cases to experience sexual satisfaction, however, this technique usually results in the residual scar on the forearm donor site. Therefore, the 
pedicled anterolateral thigh flap has begun to replace the vascularized radial forearm free flap as the first choice for surgeons because of its hidden donor area and with no need for microsurgical anastomosis (5). In all techniques, the rates of flap-related complications are high, which includes flap failure, phallic or urethral loss, urethral fistula, urethral stricture, infection, hematoma, wound dehiscence, and miscellaneous (9).

In this case, we performed the flap-based grafting therapy for penile reconstruction by using the radial thenar flap other than the radial forearm flap, leading to a smaller scar on the donor site. This man was very satisfied with the cosmetic appearance and was able to void standing from the tip of the phallus, and complications of dysuria, urethral stricture, and urinary fistula were not observed in the following period. Apart from the vascular anastomosis of the radial thenar flap grafting, neural anastomosis of penile dorsal nerve and branch of the radial nerve was also performed, since it is reported that innervated flaps had significant contribution to the successful outcomes of patient's sensation and orgasm achieving (10). At 23 months of postsurgical follow-up time, the patient reported that he had morning erections and good sensation of the flap-based phallus, though and he had not yet attempted to have sexual intercourse due to the unharmonious relationship with his spouse, unfortunately.

In addition, individualized surgical approach should be performed depending both on the patient's request and surgeon experience. Penile elongation combined with partial phalloplasty are suitable for rebuilding the partially necrotic penis (11). Primary penile replantation has good results if the penile distal stump is adequate for microanastomosis (12), and penile allotransplantation is a treatment option for patients with severe penile tissue loss and doctors with strong multidisciplinary support (13). Simultaneously or subsequently penile prosthesis implantation may be an effect approach for seeking sexual satisfaction in patients who have undergone flap phalloplasty $(14,15)$. In this case, total penile reconstruction is not required considering that the residual penile stump still has $2 \mathrm{~cm}$ long, after the release of the superficial suspensory ligament, we performed the radial thenar flap grafting therapy for partial penile reconstruction for him. Penile replantation cannot be performed due to the loss of the amputated segment, and penile prosthesis implantation was not considered due to the economic reason.

\section{Conclusions}

Innervated and vascularized radial thenar flap free grafting is an acceptable treatment option for patients with traumatic penile amputation in light of its encouraging effects for improving appearance and function in partial penile reconstruction.

\section{Acknowledgments}

Funding: None.

\section{Footnote}

Conflicts of Interest: All authors have completed the ICMJE uniform disclosure form (available at http://dx.doi. org/10.21037/tau.2019.12.12). The authors have no conflicts of interest to declare.

Ethical Statement: The authors are accountable for all aspects of the work in ensuring that questions related to the accuracy or integrity of any part of the work are appropriately investigated and resolved. Written informed consent was obtained from the patient for publication of this manuscript and any accompanying images.

Open Access Statement: This is an Open Access article distributed in accordance with the Creative Commons Attribution-NonCommercial-NoDerivs 4.0 International License (CC BY-NC-ND 4.0), which permits the noncommercial replication and distribution of the article with the strict proviso that no changes or edits are made and the original work is properly cited (including links to both the formal publication through the relevant DOI and the license). See: https://creativecommons.org/licenses/by-nc$\mathrm{nd} / 4.0 /$.

\section{References}

1. Jezior JR, Brady JD, Schlossberg SM. Management of penile amputation injuries. World J Surg 2001;25:1602-9.

2. Virasoro R, Tonkin JB, McCammon KA, et al. Penile Amputation: Cosmetic and Functional Results. Sex Med Rev 2015;3:214-22.

3. Garaffa G, Antonini G, Gentile V, et al. Phalloplasty for the genetic male. Transl Androl Urol 2012;1:103-8.

4. Garaffa G, Raheem AA, Ralph DJ. Penile fracture and penile reconstruction. Curr Urol Rep 2011;12:427-31. 
5. Rashid M, Tamimy MS. Phalloplasty: The dream and the reality. Indian J Plast Surg 2013;46:283-93.

6. Morrison SD, Shakir A, Vyas KS, et al. Phalloplasty: A Review of Techniques and Outcomes. Plast Reconstr Surg 2016;138:594-615.

7. Yao A, Ingargiola MJ, Lopez CD, et al. Total penile reconstruction: A systematic review. J Plast Reconstr Aesthet Surg 2018;71:788-806.

8. Heston AL, Esmonde NO, Dugi DD 3rd, et al. Phalloplasty: techniques and outcomes. Transl Androl Urol 2019;8:254-65.

9. Esmonde N, Bluebond-Langner R, Berli JU. Phalloplasty Flap-Related Complication. Clin Plast Surg 2018;45:415-24.

10. Ma S, Cheng K, Liu Y. Sensibility following innervated free radial forearm flap for penile reconstruction. Plast Reconstr Surg 2011;127:235-41.

11. Xiao K, Cheng K, Song N. A new surgical procedure for

Cite this article as: Lei H, Han H, Ma T, Tian L. Innervated and vascularized radial thenar flap free grafting for partial penile reconstruction after traumatic penile amputation: a case report and surgical techniques. Transl Androl Urol 2020;9(2):776-780. doi: $10.21037 /$ tau.2019.12.12 phallic reconstruction in partial penis necrosis: penile elongation in combination with glanuloplasty. Ann Plast Surg 2014;72:638-42.

12. Falcone M, Garaffa G, Raheem A, et al. Total Phallic Reconstruction Using the Radial Artery Based Forearm Free Flap After Traumatic Penile Amputation. J Sex Med 2016;13:1119-24.

13. Cetrulo CL Jr, Li K, Salinas HM, et al. Penis Transplantation: First US Experience. Ann Surg 2018;267:983-8.

14. Young EE, Friedlander D, Lue K, et al. Sexual Function and Quality of Life Before and After Penile Prosthesis Implantation Following Radial Forearm Flap Phalloplasty. Urology 2017;104:204-8.

15. Segal RL, Massanyi EZ, Gupta AD, et al. Inflatable penile prosthesis technique and outcomes after radial forearm free flap neophalloplasty. Int J Impot Res 2015;27:49-53. 